\title{
ROSINA/DFMS and IES observations of 67P: lon-neutral chemistry in the coma of a weakly outgassing comet
}

\author{
S. A. Fuselier ${ }^{1,2}$, K. Altwegg ${ }^{3}$, H. Balsiger ${ }^{3}$, J. J. Berthelier ${ }^{4}$, A. Bieler ${ }^{5}$, C. Briois ${ }^{6}$, T. W. Broiles ${ }^{1}$, J. L. Burch ${ }^{1}$, \\ U. Calmonte ${ }^{3}$, G. Cessateur ${ }^{7}$, M. Combi ${ }^{5}$, J. De Keyser ${ }^{7}$, B. Fiethe ${ }^{8}$, M. Galand ${ }^{9}$, S. Gasc ${ }^{3}$, T. I. Gombosi ${ }^{5}$, \\ H. Gunell ${ }^{7}$, K. C. Hansen ${ }^{5}$, M. Hässig ${ }^{1}$, A. Jäckel ${ }^{3}$, A. Korth ${ }^{10}$, L. Le Roy ${ }^{3}$, U. Mall ${ }^{10}$, K. E. Mandt ${ }^{1}$, \\ S. M. Petrinec ${ }^{11}$, S. Raghuram ${ }^{9}$, H. Rème ${ }^{12,13}$, M. Rinaldi ${ }^{1}$, M. Rubin ${ }^{3}$, T. Sémon ${ }^{3}$, K. J. Trattner ${ }^{14}$, C.-Y. Tzou ${ }^{3}$, \\ E. Vigren ${ }^{15}$, J. H. Waite ${ }^{1,2}$, and P. Wurz ${ }^{3}$ \\ 1 Space Science Division, Southwest Research Institute, 6220 Culebra Road, San Antonio, Texas, 78228, USA \\ e-mail: sfuselier@swri.edu \\ 2 Department of Physics and Astronomy, University of Texas at San Antonio, San Antonio, Texas TX 78249, USA \\ 3 Physikalisches Institut, University of Bern, Sidlerstrasse 5, 3012 Bern, Switzerland \\ ${ }^{4}$ LATMOS, 4 avenue de Neptune, 94100 Saint-Maur, France \\ 5 Department of Atmospheric, Oceanic and Space Sciences, University of Michigan, 2455 Hayward, Ann Arbor, MI 48109, USA \\ ${ }^{6}$ Laboratoire de Physique et Chimie de l'Environnement et de l'Espace (LPC2E), UMR 6115 CNRS-Université d'Orléans, \\ 45071 Orléans Cedex 2, France \\ 7 Belgian Institute for Space Aeronomy (BIRA-IASB), Ringlaan 3, 1180 Brussels, Belgium \\ 8 Institute of Computer and Network Engineering (IDA), TU Braunschweig, Hans-Sommer-Straße 66, 38106 Braunschweig, \\ Germany \\ 9 Space and Atmospheric Physics Group, Department of Physics, Imperial College London, Prince Consort Road, London, \\ SW7 2AZ, UK \\ 10 Max-Planck-Institut für Sonnensystemforschung, Justus-von-Liebig-Weg 3, 37077 Göttingen, Germany \\ ${ }^{11}$ Lockheed Martin Advanced Technology Center, Palo Alto, CA 94304, USA \\ 12 Université de Toulouse, UPS-OMP, IRAP, 31028 Toulouse, France \\ 13 CNRS, IRAP, 9 avenue du colonel Roche, BP 44346, 31028 Toulouse Cedex 4, France \\ 14 Laboratory of Atmospheric and Space Physics, University of Colorado, Boulder, Colorado, CO 80303, USA \\ 15 Swedish Institute of Space Physics, 75121 Uppsala, Sweden
}

Received 28 March 2015 / Accepted 7 July 2015

\section{ABSTRACT}

\begin{abstract}
Context. The Rosetta encounter with comet 67P/Churyumov-Gerasimenko provides a unique opportunity for an in situ, up-close investigation of ion-neutral chemistry in the coma of a weakly outgassing comet far from the Sun.

Aims. Observations of primary and secondary ions and modeling are used to investigate the role of ion-neutral chemistry within the thin coma.

Methods. Observations from late October through mid-December 2014 show the continuous presence of the solar wind $30 \mathrm{~km}$ from the comet nucleus. These and other observations indicate that there is no contact surface and the solar wind has direct access to the nucleus. On several occasions during this time period, the Rosetta/ROSINA/Double Focusing Mass Spectrometer measured the low-energy ion composition in the coma. Organic volatiles and water group ions and their breakup products (masses 14 through 19), $\mathrm{CO}^{+}$, and $\mathrm{CO}_{2}^{+}$(masses 28 and 44) and other mass peaks (at masses 26, 27, and possibly 30) were observed. Secondary ions include $\mathrm{H}_{3} \mathrm{O}^{+}$and $\mathrm{HCO}^{+}$(masses 19 and 29). These secondary ions indicate ion-neutral chemistry in the thin coma of the comet. A relatively simple model is constructed to account for the low $\mathrm{H}_{3} \mathrm{O}^{+} / \mathrm{H}_{2} \mathrm{O}^{+}$and $\mathrm{HCO}^{+} / \mathrm{CO}^{+}$ratios observed in a water dominated coma. Results from this simple model are compared with results from models that include a more detailed chemical reaction network.

Results. At low outgassing rates, predictions from the simple model agree with observations and with results from more complex models that include much more chemistry. At higher outgassing rates, the ion-neutral chemistry is still limited and high $\mathrm{HCO}^{+} / \mathrm{CO}^{+}$ratios are predicted and observed. However, at higher outgassing rates, the model predicts high $\mathrm{H}_{3} \mathrm{O}^{+} / \mathrm{H}_{2} \mathrm{O}^{+}$ratios and the observed ratios are often low. These low ratios may be the result of the highly heterogeneous nature of the coma, where $\mathrm{CO}$ and $\mathrm{CO}_{2}$ number densities can exceed that of water.
\end{abstract}

Key words. comets: individual: 67P/Churyumov-Gerasimenko - solar wind - plasmas - molecular processes - methods: data analysis

\section{Introduction}

Because of their low gravity and high volatile gas content, comets outgas neutrals (primarily $\mathrm{H}_{2} \mathrm{O}, \mathrm{CO}, \mathrm{CO}_{2}$ ), forming extended comae. Neutrals from the comet are ionized by extreme ultraviolet (EUV) solar photons, charge-exchange with solar wind ions, and are ionized by electron impact ionization from solar wind and suprathermal cometary electrons. Of these processes, photoionization appears to dominate at perihelion distances of $\sim 1$ AU (e.g., Ip 2004), but ion charge-exchange also 
contributes to the total ion density. Energetic electrons in the solar wind (e.g., Rubin et al. 2009) and photoelectrons in highdensity coma (e.g., Bhardwaj 2003) produce additional ions by electron impact ionization.

Newly ionized molecules are "picked up" by the solar wind electric field. This pickup process slows and deflects the solar wind and, as more and more ions are picked up, a ring distribution of cometary ions is created around the solar wind magnetic field (e.g., Galeev et al. 1985; Coates et al. 1989). This distribution is also often referred to as a ring-beam distribution (e.g., Ip 2004). This ring distribution is highly agyrotropic and much more beam-like at scale sizes much smaller than a gyroradius of a cometary ion.

If outgassing is weak and the solar wind slows gradually, then the solar wind may or may not deflect around the comet nucleus before it hits the surface. As the outgassing rate increases, a contact surface forms (e.g., Schmidt \& Wegmann 1982; Neubauer et al. 1986) and the solar wind plasma and magnetic field no longer have access to the nucleus. Inside the contact surface, cometary neutrals and ions propagate radially away from the nucleus until they arrive at the boundary. Ions are deflected tailward of the comet while neutrals propagate through it into the cometosheath between the bow shock and contact surface. Outside the contact surface, newly created cometary ions from these neutrals are picked up by the shocked solar wind. The interaction near the contact surface is complex (e.g., Ip \& Axford 1987). However, the interaction between cometary ions and neutrals inside the contact surface is somewhat simplified because the solar wind is excluded from this region and the ion motion and temperature are governed by collisional interactions with the neutral gas.

There is a rich ion-neutral chemistry in the comae of moderate to highly active comets. This chemistry has been modeled in detail for comets near perihelion and for high outgassing rates, such as comet Halley (e.g., Wegmann et al. 1987; Haider \& Bhardwaj 2005; Huebner et al. 1991; Rubin et al. 2009) and moderate outgassing rates, such as 67P (Vigren \& Galand 2013). Observations (e.g., Balsiger et al. 1986; Altwegg et al. 1993, 1994; Geiss et al. 1991) and modeling show that, because of extensive ion-neutral chemistry, the abundances of ion species certainly do not reflect neutral abundances in the coma. The extent and characteristics of the chemistry strongly depends on the neutral density and the fact that cometary comae are not in chemical equilibrium. In fact, the transient nature of the cometary atmosphere strongly drives the coma out of equilibrium. Thus, the rates of various reactions are critically important in determining the ion species that are produced and temporarily reside in the coma.

The in situ study of the ion-neutral interactions in the comae of comets has been limited to very active comets near perihelion (near $1 \mathrm{AU}$ ) and observations relatively far (from hundreds to tens of thousands of $\mathrm{km}$ ) from the nucleus. In situ measurements at comets near perihelion were made when outgassing rates were from $10^{28}$ molecules/s for comets Giacobini-Zinner and GriggSkjellerup (e.g., Fuselier et al. 1986; Benna \& Mahaffy 2006) to nearly two orders of magnitude higher for comet Halley (e.g., Balsiger et al. 1986; Altwegg et al. 1993, 1994; Geiss et al. 1991; Huebner et al. 1992; Rubin et al. 2009).

The arrival of the Rosetta spacecraft at $67 \mathrm{P} /$ ChuryumovGerasimenko (67P) provides a unique opportunity for an upclose study of a weakly outgassing comet far from the Sun and far from its perihelion. Rosetta encountered the comet more than 3.5 AU from the Sun and, up to March 2015, the Rosetta orbiter has spent a long time within $50 \mathrm{~km}$ of the nucleus. In August, when $67 \mathrm{P}$ was about $3.5 \mathrm{AU}$ from the Sun, the water production rate was about $4 \times 10^{25}$ molecules/s (Gulkis et al. 2015). From October through December 2014, when 67P was between 3.2 and 2.8 AU from the Sun, the lower limit on the water production rate was only marginally higher, about $8 \times 10^{25}$ molecules $/ \mathrm{s}$ (Bieler et al. 2015). Diurnal variations in the density at the spacecraft (Hässig et al. 2015; Bieler et al. 2015) are most likely the result of a combination of locations in the coma and changes in the outgassing rate over one cometary rotation. This paper presents preliminary analysis of some representative in situ ion composition observations near comet $67 \mathrm{P}$ and discusses the observations in relation to the neutral composition of the coma, the comasolar wind interaction, and ion-neutral reactions. It demonstrates that the chemistry in the thin coma can be described with a simple model, and where the simple description breaks down, and indicates where both the simple and more complex chemistry models require additional input.

\section{Instrumentation}

Ion observations in this paper are from the Rosetta Orbiter Spectrometers for Ion and Neutral Analysis (ROSINA)/Double Focusing Mass Spectrometer (DFMS; Balsiger et al. 2007). DFMS is a magnetic ion and neutral mass spectrometer with a mass per charge $(\mathrm{u} / \mathrm{e})$ range from $12 \mathrm{u} / \mathrm{e}$ to $150 \mathrm{u} / \mathrm{e}$ and a mass resolution of 3000 at $1 \%$ peak height. The spectrometer has two basic operating modes: a gas (or neutral) mode for measuring cometary neutrals and an ion mode for measuring cometary ions. These modes have two basic mass resolutions: high (3000 at 1\% peak height) and low (300 at 1\% peak height). High-resolution measurements are about a factor of 10 less sensitive than lowresolution measurements. Most of the time, DFMS is operated in the neutral mode. However, there were several occasions from the end of October through December when the spectrometer was operated continuously in the ion mode for several to many hours at a time.

In the ion mode, the ion source filament (which emits the electrons used to ionize the neutrals in the ion source) is switched off. Cometary ions drift into the entrance aperture, which, for the ion mode is $9^{\circ} \times 6^{\circ}$ (Schläppi 2011). For observations in this paper, DFMS accepted ions with an external energy of between 0 and approximately $45 \mathrm{eV}$. This energy range is dictated by the spacecraft potential (which probably was negative for the time period) and the $\Delta E / E$ of the spectrometer.

After energy selection, a permanent magnet is used to separate masses and ions exiting the magnet are directed onto one of three detectors. For the observations in this paper, the microchannel plate (MCP) detector was used. In low-mass resolution, the mass range for one measurement is typically $>1 \mathrm{u} / \mathrm{e}$ and several integer mass peaks are recorded simultaneously on the MCP detector. In high-mass resolution, the mass range is always $<1 \mathrm{u} / \mathrm{e}$ and only one integer mass peak (which may be resolved into several masses) is recorded on the detector. For the observations in this paper, one low-mass resolution and one high-mass resolution ion mode was used. Both modes stepped through a range of masses from $13 \mathrm{u} / \mathrm{e}$ to either $100 \mathrm{u} / \mathrm{e}$ (low-resolution mode) or $150 \mathrm{u} / \mathrm{e}$ (high-resolution mode).

In addition to the ion and neutral measurements from DFMS, total neutral number densities in this paper are from the ROSINA/Cometary Pressure Sensors (COPS) nude ion gauge (Balsiger et al. 2007). The COPS nude ion gauge is an extractortype ionization gauge that measures total gas density at the spacecraft. 


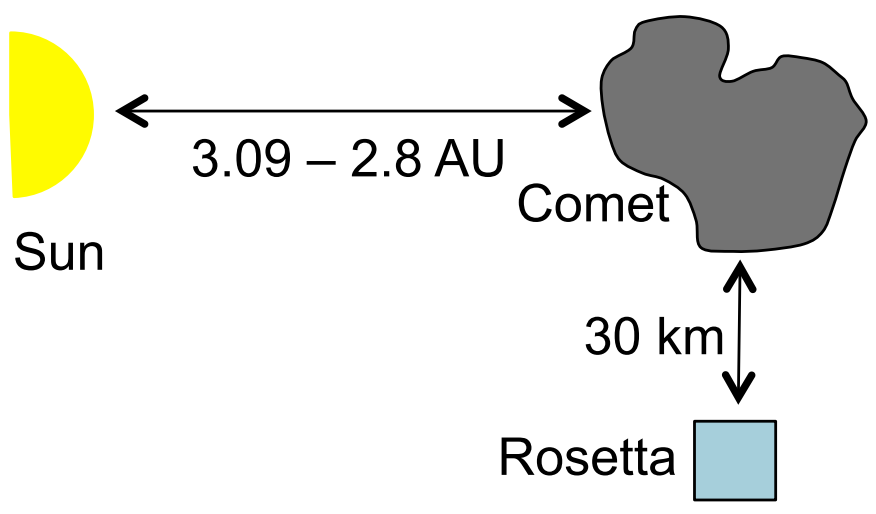

Fig. 1. Schematic location of the comet, spacecraft, and Sun at the end of October 2014. The spacecraft was $\sim 30 \mathrm{~km}$ from the comet in a bound, terminator orbit. Other ion observations in this paper are from a distance of $30 \mathrm{~km}$.

Solar wind ion and electron measurements in this paper are from the Rosetta Ion and Electron Sensor (IES; Burch et al. 2007). IES is part of the Rosetta Plasma Consortium (RPC), which includes other plasma and magnetic field sensors. IES was used here to determine whether the solar wind was present at the spacecraft when the ion composition measurements were made.

\section{Conditions at the comet from October through December 2014}

Figure 1 shows a schematic representation of the relative Rosetta spacecraft, comet, and Sun positions and distances for 30 October, 2014. The spacecraft was in orbit around the comet at a distance of approximately $30 \mathrm{~km}$ and the DFMS field of view was directed nearly continuously at the comet. In late October, the comet and spacecraft were 3.09 AU from the Sun. In November and early December, most of the other ion observations were made at a distance of $30 \mathrm{~km}$ from the comet, sometimes in similar bound, terminator orbits. Some observations at $20 \mathrm{~km}$ were made that are used here for illustrative purposes, but did not enter into in the calculations of mass ratios.

From the end of October to the end of December, the cometSun distance changed from 3.09 AU to 2.8 AU and IES observed the solar wind essentially continuously. Figure 2 shows an example IES angle-energy plot of the solar wind and cometary ion fluxes. The Sun is in the upper left corner and the comet is below in this angle-energy plot. Solar wind $\mathrm{H}^{+}$and $\mathrm{He}^{2+}$ propagate away from the Sun (and are therefore observed in IES anodes that view the Sun) with a velocity of about $370 \mathrm{~km} \mathrm{~s}^{-1}(0.7 \mathrm{keV} / \mathrm{e}$ for protons). IES measures energy per charge without mass discrimination. Therefore, $\mathrm{He}^{2+}$ appears at twice the energy per charge of $\mathrm{H}^{+}$in Fig. 2. The direction of propagation is deflected somewhat from the Sun direction because of the cometary ion pickup process described in the introduction (see also Broiles et al. 2015; Nilsson et al. 2015). The $\mathrm{He}^{+}$distribution is produced by charge exchange of solar wind $\mathrm{He}^{2+}$ with cometary neutrals (Shelley et al. 1987; Burch et al. 2015). Low-energy cometary ions are observed in the sectors viewing opposite the comet direction.

The presence of the solar wind $30 \mathrm{~km}$ from the comet indicates that there is no contact surface sunward of the spacecraft location. In addition, the weak deflection of the solar wind indicates that it probably has access to the surface of the nucleus.

There is additional evidence of solar wind access to the surface. Sputtering of dust refractory material from the surface of
67P (Wurz et al. 2015) is observed. When Rosetta was $10 \mathrm{~km}$ from the comet in mid-October 2014, DFMS observed nonvolatile refractory species $(\mathrm{Na}, \mathrm{K}, \mathrm{Si}$, and $\mathrm{Ca})$ in the coma. Observations (not shown here) of sputtered dust refractory species during the period from 30 October through 15 December 2014 demonstrates that, at very least, there was intermittent sputtering by solar wind impact during the times when the ion measurements in this paper were made.

With no contact surface at the comet, newly ionized cometary molecules are picked up by the solar wind. A velocity space diagram of this pickup process is shown in Fig. 3. The magnetic field is assumed to be in the ecliptic and in a direction consistent with the deflection of the solar wind by cometary ion pickup (see Broiles et al. 2015). Newly created ions are at nearly zero velocity relative to the comet. When fully picked up, these ions will form a ring distribution in velocity space that is centered on the $\mathrm{E} \times \mathrm{B}$ drift velocity and has a bulk flow antiparallel to the magnetic field $\left(V_{-\|}\right)$as illustrated in Fig. 3. DFMS accepts a small slice of velocity space near zero velocity (the negative spacecraft potential helps in this case). Therefore, the ion flux measured by DFMS strongly depends on the magnetic field orientation, the direction to the comet, and the amount of deflection and energization that the ions experience in the pickup process before their arrival at the spacecraft. Nilsson et al. (2015) described observational evidence at $67 \mathrm{P}$ of this energization in the initial phase of the pickup process. Broiles et al. (2015) demonstrated that the deflection of the solar wind is a consequence of this initial pickup process. To understand the conditions in the partially ionized coma, it is important to understand how the ion pickup timescale is related to the propagation time from the comet to the spacecraft. The timescale for pickup, propagation time, and an estimate of the mean free path of ions in the coma are presented in Table 1.

As Table 1 demonstrates, the propagation time from the comet to the spacecraft is short compared to the gyroperiod of a water ion that is created near the comet surface. Thus, DFMS observes ions created all along the path from the comet surface to the spacecraft. An ion created at the comet experiences the solar wind convective electric field as it propagates to the spacecraft. Assuming a maximum convective electric field, Table 1 shows that an ion created at the comet will gain $11 \mathrm{eV}$ of energy by the time it is $30 \mathrm{~km}$ from the comet. This small amount of energy gained keeps the newly created ion within the energy window of DFMS. Ions created far sunward of the spacecraft that are picked up by the solar wind and convected back to the spacecraft will have too high an energy (and will be deflected away from the comet) and will not be observed by DFMS.

The mean free path for ions created near the comet is somewhat longer than the distance between the spacecraft and the comet. The mean free path in Table 1 assumes a constant neutral density from the comet to the spacecraft. In reality, the density is about an order of magnitude higher within $10 \mathrm{~km}$ of the comet, which reduces the mean free path from $100 \mathrm{~km}$ to about $30 \mathrm{~km}$ in that region. Therefore, newly created cometary ions are likely to suffer at most one collision with the neutrals in the coma as they propagate from the comet to the spacecraft. Since collisions are necessary for coma ion-neutral chemistry, these conditions indicate that the chemical interactions in the coma are limited.

\section{Ion composition observations in the coma}

Figure 4 shows two days of neutral and ion measurements of mass 18. Background (primarily neutral background from the spacecraft) was not subtracted from these measurements, but the 


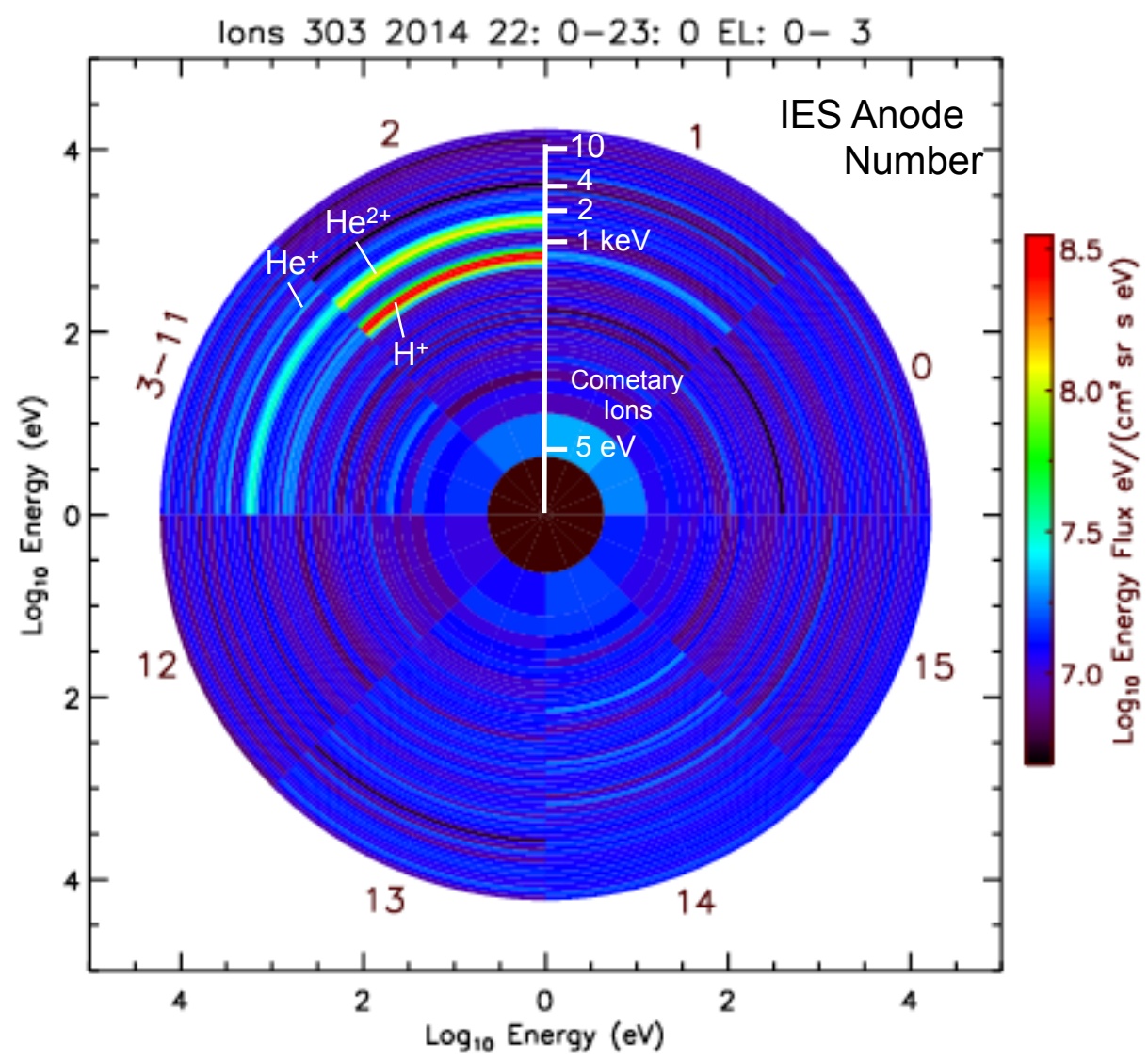

Fig. 2. Rosetta IES observations of solar wind ions on 30 October 2014 from 2200 to 2300 UT. This energy-angle plot shows the arrival anode of solar wind and cometary ion fluxes. The directions to the Sun and comet are shown. Solar wind $\mathrm{H}^{+}$and $\mathrm{He}^{2+}$ are propagating at the same speed of $370 \mathrm{~km} \mathrm{~s}^{-1}$ (and therefore $\mathrm{He}^{2+}$ appears at twice the $\mathrm{H}^{+}$energy per charge in the IES electrostatic analyzer). The solar wind is not propagating radially away from the Sun because of cometary ion pickup. The extent and direction of the deflection depend on the comet outgassing rate and the orientation of the solar wind magnetic field. The existence of $\mathrm{He}^{+}$is further evidence of the interaction with the comet coma. It is created by charge exchange of solar wind $\mathrm{He}^{2+}$ with cometary neutrals.

Table 1. Estimates of pickup ion parameters in the coma and assumptions that are used to derive these parameters.

\begin{tabular}{l|l|l|l}
\hline \hline Assumptions & $\begin{array}{l}\text { Measured quantities } \\
(30 \text { October 2014) }\end{array}$ & Derived parameters & Values \\
\hline $\begin{array}{l}1 \mathrm{nT} \text { solar wind magnetic } \\
\text { field }\end{array}$ & $V_{\mathrm{SW}}=370 \mathrm{~km} \mathrm{~s}^{-1}$ & $\begin{array}{l}\text { Gyroradius }\left(\mathrm{H}_{2} \mathrm{O}^{+}\right) \\
\text {Gyroperiod }\left(\mathrm{H}_{2} \mathrm{O}^{+}\right)\end{array}$ & $\begin{array}{l}7 \times 10^{4} \mathrm{~km} \\
1200 \mathrm{~s}\end{array}$ \\
\hline $\begin{array}{l}1 \mathrm{nT} \text { solar wind magnetic } \\
\text { field perpendicular to } V_{\mathrm{SW}}\end{array}$ & $V_{\mathrm{SW}}=370 \mathrm{~km} \mathrm{~s}^{-1}$ & $\begin{array}{l}\text { Solar wind convective elec- } \\
\text { tric field energy gain for an } \\
\text { ion after } 30 \mathrm{~km} \text { propagation }\end{array}$ & $0.37 \mathrm{mV} / \mathrm{m}$ \\
$11 \mathrm{eV}$ \\
\hline $\begin{array}{l}\text { Neutral gas outflow speed } \\
\text { from comet }=0.7 \mathrm{~km} \mathrm{~s}^{-1}\end{array}$ & $\begin{array}{l}\text { Distance: Rosetta to comet } \\
\text { nucleus }=30 \mathrm{~km}\end{array}$ & $\begin{array}{l}\text { Propagation time from comet } \\
\text { to Rosetta }\left(\mathrm{H}_{2} \mathrm{O}, \mathrm{H}_{2} \mathrm{O}^{+}\right)\end{array}$ & $43 \mathrm{~s}$ \\
\hline $\begin{array}{l}\text { Neutral gas temperature be- } \\
\text { tween 200 and } 1000 \mathrm{~K}\end{array}$ & $\begin{array}{l}\text { Neutral number density at } \\
\text { Rosetta: } 10^{7} \text { molecules } \mathrm{cm}^{-3}\end{array}$ & Mean free path & $\sim 70-300 \mathrm{~km}$ \\
\hline
\end{tabular}

neutral background is orders of magnitude lower than the neutral signal and the ion background is considerably lower than the ion signal. This time period was selected because it contains a short period of ion observations that is bracketed by sustained neutral observations. The COPS total density (green dots) shows variations at a period of approximately six hours. These diurnal variations are associated with times when the "neck" region of the comet is in view (Hässig et al. 2015; Bieler et al. 2015). The ion-neutral chemistry in the coma will have time variations at the same period. Also shown in Fig. 4 is the DFMS mass 18 signal (in arbitrary units) for neutrals and for ions for two periods of ion measurements. The neutral measurements of mass 18 (mostly neutral $\mathrm{H}_{2} \mathrm{O}$ ) show the same diurnal variations as those in the
COPS total neutral density. The similarities in the two measurements are consistent with a water-dominated neutral coma, at least for this time period. In the ion mode, the mass 18 signal is almost four orders of magnitude lower than the neutral signal. The diurnal variations are no longer evident even though the spectrometer still measures water (ions) and the COPS total neutral density still exhibits diurnal variations. The statistical uncertainties are of about the symbol size for all DFMS measurements in Fig. 4; therefore, counting statistics cannot explain the lack of diurnal variations in the ion measurements. This lack of variation in the ion time series probably is the result of the differences between the ion and neutral coma and the effects of the pickup ion process discussed in the introduction. 


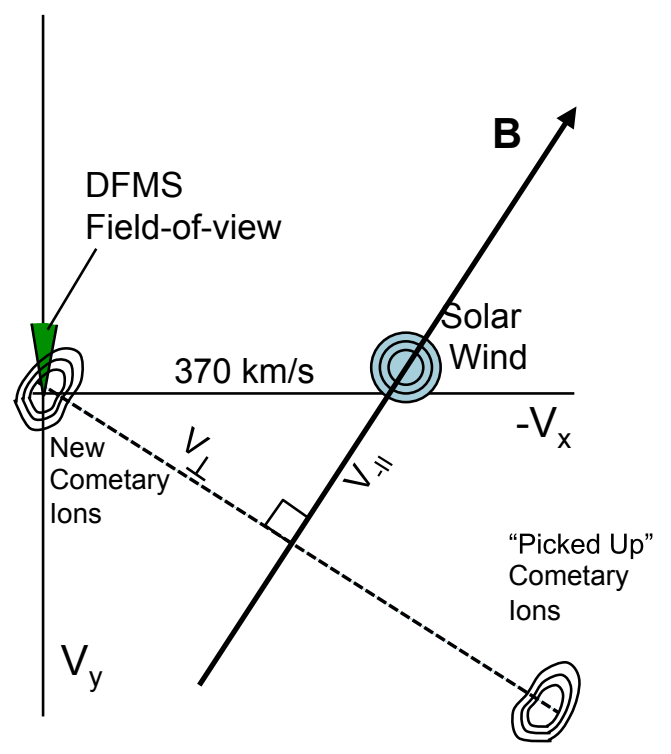

Fig. 3. Schematic representation of cometary ion pickup. The ecliptic plane is shown and the magnetic field is assumed to be located in that plane. Cometary ions are created at rest with respect to the solar wind. These ions respond to the solar wind electric field by gyrating around the solar wind magnetic field. When fully picked up, the cometary ions form a ring distribution. The intersection of this ring with the plane that contains the magnetic field and the solar wind is shown. In response, the solar wind is deflected. The relatively small deflection shown in this schematic is consistent with the deflection in Fig. 2. DFMS has a very narrow field of view (shown by the green wedge) and detects lowenergy ions from the comet. It does not detect the entire cometary ion distribution because pickup ions move in a direction and have an energy that is outside of the field of view and energy window of DFMS.

Two competing effects complicate the direct comparison of ion and neutral signals in Fig. 4 and the determination of the ion density in the coma from DFMS measurements. The first effect is the difference of the ion and neutral detection efficiencies for DFMS. The second effect is that DFMS most likely samples the entire neutral population in the coma, but only samples a small part of the ion population. Of these, the second effect is probably more significant.

As illustrated in Fig. 3, only a small part of the ion flux is detected by the relatively narrow field of view of the spectrometer. Very low energy ions are detected because the spacecraft potential is negative. However, the flux and direction of arrival of these ions are a complicated function of the shape of the spacecraft potential, which is not well known. Furthermore, ion pickup deflects ions beyond the field of view and shifts them out of the energy range of the spectrometer.

Using the deflection of the solar wind near the comet (similar to the deflection seen in Fig. 2), Broiles et al. (2015) estimated the coma ion density to be between 0.4 and $3 \mathrm{~cm}^{-3}$ for two intervals in October 2014 and January 2015. Because ions must be picked up in order to deflect the solar wind, this density estimate is probably representative of ion densities somewhat farther sunward of the spacecraft. The densities at the spacecraft may be higher. Thus, it is reasonable to conclude that DFMS, with its very small sample of velocity space, may be detecting much less than 1 percent of the total ion flux.

Because DFMS misses a large portion of the ion distribution, absolute fluxes of the ion species are not very meaningful. However, the ratios of individual species are excellent representations of the ion neutral chemistry in the coma. Figure 5 shows
Table 2. Ion mass peaks observed by DFMS and the predominant ion in the peak, determined from high-resolution mass spectra.

\begin{tabular}{cc}
\hline \hline Mass per charge $(\mathrm{u} / \mathrm{e})$ & Predominant ion \\
\hline 14 & $\mathrm{CH}_{2}{ }^{+}$ \\
\hline 15 & $\mathrm{CH}_{3}{ }^{+}$ \\
16 & $\mathrm{O}^{+}$ \\
17 & $\mathrm{OH}^{+}$ \\
18 & $\mathrm{H}_{2} \mathrm{O}^{+}$ \\
19 & $\mathrm{H}_{3} \mathrm{O}^{+}$ \\
28 & $\mathrm{CO}^{+}$ \\
44 & $\mathrm{CO}_{2}{ }^{+}$ \\
\hline
\end{tabular}

a low-resolution ion spectrum taken on 4 November 2014. The spectrum, ranging from mass per charge $=13.5$ to $19.5 \mathrm{u} / \mathrm{e}$, is a combination of four individual mass spectra. It was taken $30 \mathrm{~km}$ from the comet at a longitude of $-31^{\circ}$ and a latitude of $19^{\circ}$. In the mass range from 13.5 to $19.5 \mathrm{u} / \mathrm{e}$, there may be a peak at mass 14 , and there are certainly peaks at masses 15 through 19 . Peaks at masses $14.4 \mathrm{u} / \mathrm{e}$ and $17.4 \mathrm{u} / \mathrm{e}$ are probably not real. They represent the variable offset signal across the MCP detector that forms an apparent peak when the end of one spectrum is sequenced onto the beginning of the next spectrum. Strong candidates for the masses that are clearly observed include water group and organic products. From high to low mass these candidates include, $\mathrm{H}_{3} \mathrm{O}^{+}$(mass 19), $\mathrm{H}_{2} \mathrm{O}^{+}$(mass 18 ), $\mathrm{OH}^{+}$(mass 17 ), $\mathrm{O}^{+}$and $\mathrm{CH}_{4}{ }^{+}$(mass 16) $\mathrm{CH}_{3}{ }^{+}$(mass 15 ), and possibly $\mathrm{CH}_{2}{ }^{+}$(mass 14). Nitrogen-bearing molecules are probably at much lower number densities because of the paucity of nitrogen in the coma (Rubin et al. 2015; Le Roy et al. 2015). The exception might be products of $\mathrm{NH}_{3}$ (such as $\mathrm{NH}_{3}{ }^{+}$at mass 17) because $\mathrm{NH}_{3}{ }^{+}$can be a few percent in the ionized comae (Allen et al. 1987; Haider et al. 1993). At a few percent of the water ion density, this molecule plays an important role in ion-neutral chemistry when the total ion density is high (Allen et al. 1987; Geiss et al. 1991; Altwegg et al. 1993; Vigren \& Galand 2013).

High-resolution mass spectra (not shown here) distinguish carbon-, nitrogen-, and oxygen-based molecules and confirm the major mass peaks and some of the minor ones. The mass peaks and the predominant ions that are confirmed by these highresolution spectra are shown in Table 2.

Ions in the mass range from 14 to $18 \mathrm{u} / \mathrm{e}$ are composed of water and its products and products of carbon-hydrogen molecules. Since $\mathrm{O}^{+}$dominates at mass 16 , the origin of $\mathrm{CH}_{3}{ }^{+}$and $\mathrm{CH}_{2}{ }^{+}$ probably is a mixture of parent (neutral) molecules that includes $\mathrm{CH}_{4}$ but may have significant contributions from higher mass molecules such as $\mathrm{C}_{2} \mathrm{H}_{6}$. The contributions of higher mass molecules such as $\mathrm{C}_{2} \mathrm{H}_{6}$ to masses 14 and 15 are important for the overall understanding of the ions that make up masses 27 through 29. The origin of $\mathrm{H}_{3} \mathrm{O}^{+}$in Table 2 is discussed below.

Figure 6 shows low-resolution ion spectra for two different time periods. The spectra, which span the mass range from mass 26 to $30 \mathrm{u} / \mathrm{e}$ are a combination of two individual mass spectra. These spectra from the two time periods illustrate the range of variations in the mass peaks for the mass range around mass 28 . Spectrum (a) was taken $30 \mathrm{~km}$ from the comet at a longitude of $-161^{\circ}$ and a (southern hemisphere) latitude of $-42^{\circ}$. Spectrum (b) was taken $30 \mathrm{~km}$ from the comet at a longitude of $64^{\circ}$ and a (northern hemisphere) latitude of $44^{\circ}$. Spectrum (a) shows mass peaks at mass $26,27,28$, and 29 but no mass peak at mass 30. At low-resolution, $\mathrm{CN}^{+}$cannot be distinguished from $\mathrm{C}_{2} \mathrm{H}_{2}{ }^{+}$or $\mathrm{HCN}^{+}$from $\mathrm{C}_{2} \mathrm{H}_{3}{ }^{+}$. However, the mass separation is sufficient to conclude that the mass peaks at mass 28 and 29 are dominated by $\mathrm{CO}^{+}$and $\mathrm{HCO}^{+}$, respectively. The dominance of 


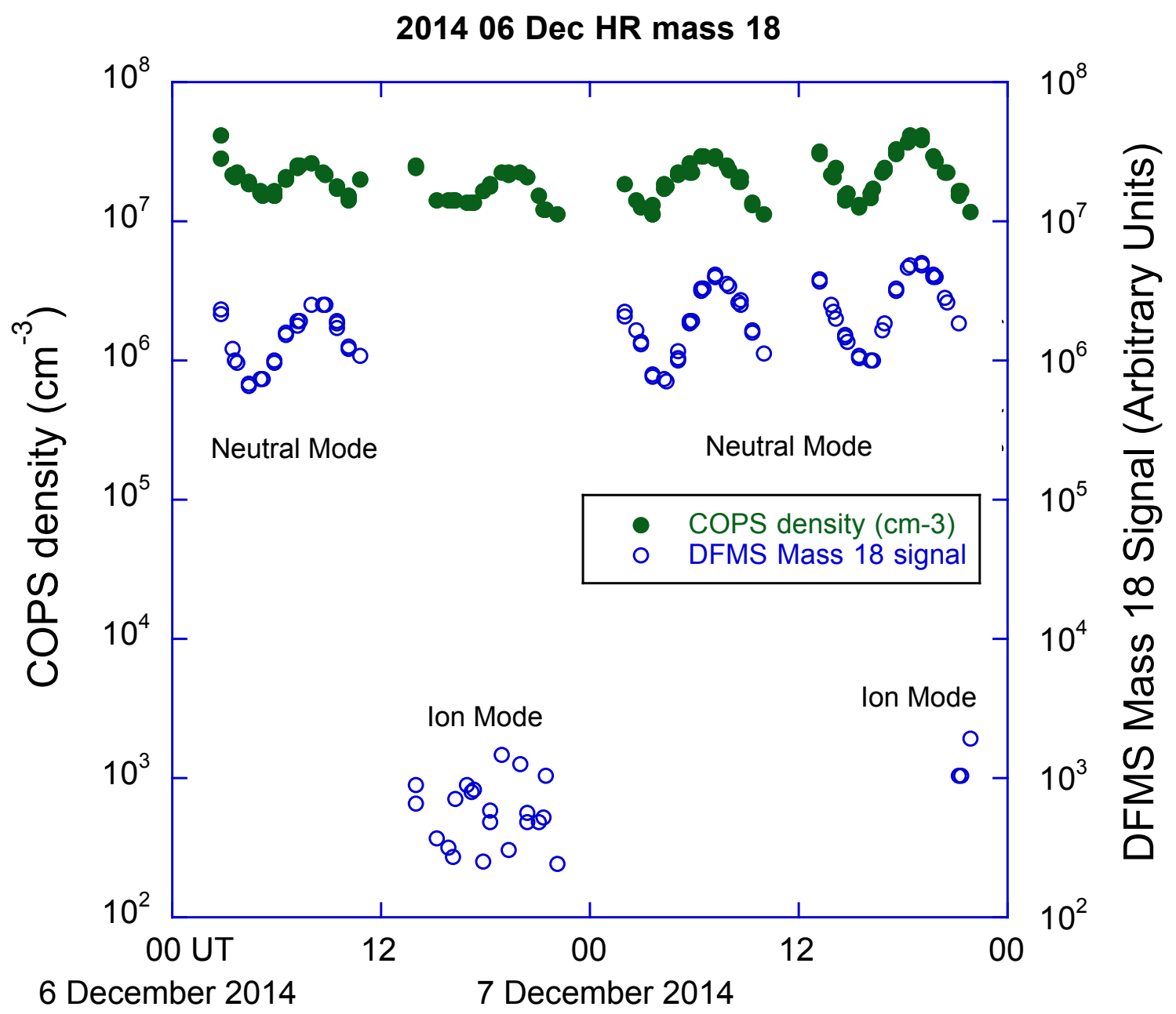

Fig. 4. Two days of neutral and ion measurements from ROSINA/COPS and DFMS. The measurements were taken $20 \mathrm{~km}$ from the comet, span all longitudes, and the latitude range from 0 to $-46^{\circ}$. COPS measurements of the total neutral density at the spacecraft (green dots) show diurnal variations of up to a factor of 5 (ranging from $\sim 1 \times 10^{7} \mathrm{~cm}^{-3}$ to $5 \times 10^{7} \mathrm{~cm}^{-3}$ ) with a six-hour period. DFMS observations of neutral $\mathrm{H}_{2} \mathrm{O}$ (mass 18 , with the intensity in arbitrary units) show the same diurnal variations. Ion measurements from 12 to 24 UT on 6 December 2014 and from 23 to 24 UT on 7 December 2014 are almost four orders of magnitude lower than the neutral signal. Accounting for differences in the efficiencies for detecting ions and neutrals, the ion density measured by DFMS is about $0.1 \mathrm{~cm}^{-3}$.

$\mathrm{CO}^{+}$at mass 28 is confirmed using high-resolution mass spectra from other times (not shown).

Spectrum (b) in Fig. 6 shows a very different spectrum from spectrum (a). In this spectrum, there are peaks at mass 27 and 29 and possibly weak peaks at mass 28 and 30 . As in spectrum (a), the mass resolution is not sufficient to distinguish $\mathrm{HCN}^{+}$from $\mathrm{C}_{2} \mathrm{H}_{3}{ }^{+}$. However, unlike spectrum (a), there is very little $\mathrm{CO}^{+}$ and, although $\mathrm{HCO}^{+}$still dominates mass 29 , there probably is a contribution from $\mathrm{C}_{2} \mathrm{H}_{5}{ }^{+}$. The weak peak at mass 30 may be $\mathrm{C}_{2} \mathrm{H}_{6}{ }^{+}$. The makeup of the mass 29 peak is discussed in detail in Sect. 5 .

In addition to the mass peaks shown in Figs. 5 and $6, \mathrm{CO}_{2}{ }^{+}$ (mass 44, not shown) is regularly observed in the coma. Other mass peaks from 30 to $50 \mathrm{u} / \mathrm{e}$ are observed very rarely or not observed at all above the DFMS background. In particular, there is no signal observed at mass $32\left(\mathrm{~S}^{+}\right.$?). $\mathrm{S}^{+}$was observed in the coma of comet Halley (Balsiger et al. 1986). Higher mass water cluster ions $\left(\mathrm{H}_{2} \mathrm{O}\right)_{n}-\mathrm{H}_{2} \mathrm{O}^{+}$(i.e., multiples of 18 or 19) were not observed either. These water clusters have been observed in the water-ice plume at Enceladus (Hill et al. 2012) and are predicted for 67P near perihelion (Vigren \& Galand 2013).
In Fig. 5, the $\mathrm{H}_{2} \mathrm{O}^{+}$(mass 18) intensity was greater than that for $\mathrm{H}_{3} \mathrm{O}^{+}$(mass 19). In Fig. 6, the $\mathrm{CO}^{+}$(mass 28) dominates over mass $29\left(\mathrm{HCO}^{+}\right)$in spectrum (a) and is much lower than mass $29\left(\mathrm{HCO}^{+}, \mathrm{C}_{2} \mathrm{H}_{5}{ }^{+}\right.$?) in spectrum (b). $\mathrm{H}_{3} \mathrm{O}^{+}$and $\mathrm{HCO}^{+}$are good indicators of the level of ion-neutral chemistry in the coma. They are formed by interaction of a newly created $\mathrm{H}_{2} \mathrm{O}^{+}$ion with $\mathrm{H}_{2} \mathrm{O}$ and $\mathrm{CO}$ molecules in the coma through the ion-molecule reactions:

$\mathrm{H}_{2} \mathrm{O}^{+}+\mathrm{H}_{2} \mathrm{O} \rightarrow \mathrm{H}_{3} \mathrm{O}^{+}+\mathrm{OH}$ rate constant $=1.85 \times 10^{-9} \mathrm{~cm}^{3} \mathrm{~s}^{-1}$

$\mathrm{H}_{2} \mathrm{O}^{+}+\mathrm{CO} \rightarrow \mathrm{HCO}^{+}+\mathrm{OH}$ rate constant $=4.25 \times 10^{-10} \mathrm{~cm}^{3} \mathrm{~s}^{-1}$

where the rate constants in Eqs. (1) and (2) were used in a coma model by Rubin et al. (2009) and are tabulated in Anicich (1993).

The $\mathrm{H}_{3} \mathrm{O}^{+} / \mathrm{H}_{2} \mathrm{O}^{+}$ratio increases with increasing neutral density in the coma. For example, at Halley near perihelion, the ratio was $\sim 3-5$ at distances in excess of $4000 \mathrm{~km}$ from the nucleus (Allen et al. 1987). With its much lower coma density, the $\mathrm{H}_{3} \mathrm{O}^{+} / \mathrm{H}_{2} \mathrm{O}^{+}$ratio at $67 \mathrm{P}$ might be much lower than that at Halley, even at much smaller distances. Figure 7 shows 


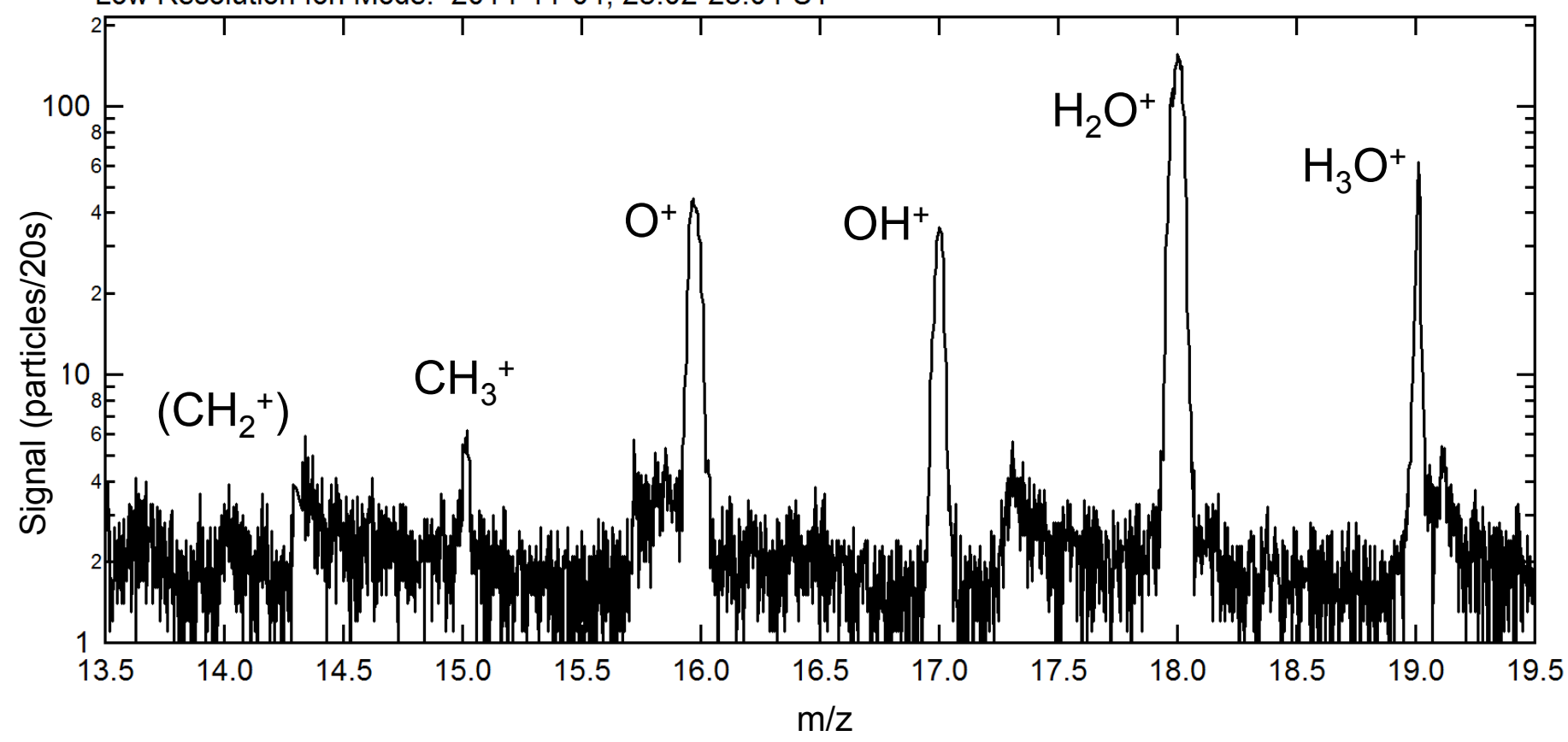

Fig. 5. Low-resolution ion spectrum from mass 13.5 to $19.5 \mathrm{u}$ /e. There may be a peak at mass 14 (probably $\mathrm{CH}_{2}^{+}$) and there are certainly peaks at mass 15 through mass 19 (primarily water group ions, with $\mathrm{H}_{3} \mathrm{O}^{+}$at mass 19 , and $\mathrm{O}^{+}, \mathrm{CH}_{3}^{+}$, at mass 16 and 15 , respectively). Apparent peaks at masses 13.6, 14.4, and 17.4 are not real. They are the result of a combination of mass spectra with a gradient in the offset across the DFMS detector.

the mass $19\left(\mathrm{H}_{3} \mathrm{O}^{+}\right) /$mass $18\left(\mathrm{H}_{2} \mathrm{O}^{+}\right)$ratio (top panel) and the mass $29\left(\mathrm{HCO}^{+}, \mathrm{C}_{2} \mathrm{H}_{5}{ }^{+}\right.$?)/mass $28\left(\mathrm{CO}^{+}\right)$ratio (bottom panel) as a function of the total neutral density at the Rosetta spacecraft. All ion measurements were used starting 30 October and extending through 15 December 2014 when the spacecraft was $30 \mathrm{~km}$ from the comet. Table 3 shows the dates, times, and locations for the observations in Fig. 7. High-resolution ion measurements were used for the mass 19 to mass 18 ratio because the low-resolution mode (used, for example, to create Fig. 5) places the mass 19 peak near the very edge of the MCP detector. At the edge of the detector, offset subtraction is more difficult and the relative gain at that location is not as well defined because of edge effects on the detector. The high-resolution mode places the mass 19 and the mass 18 peaks in the center of the detector in sequential mass spectra. At this location on the detector, offset subtraction and relative gain on the detector are better defined. Furthermore, the subtraction and gain correction are the same for the two mass peaks, resulting in a ratio where the accuracy is determined by the counting statistics. Low-resolution ion measurements were used for the mass 29 to mass 28 ratio because count rates for mass 29 ions were substantially lower than those for mass 19 and mass 18 ions. For example, Fig. 6 spectrum (a) shows that the count rate for mass 29 was almost an order of magnitude lower than that for mass 19 in Fig. 5. Because of the variable pixel gain (due to progressive MCP degradation that is more pronounced in the center of the detector than at the edges) and the overall lower signal on mass 29 and 28, the uncertainties in the mass 29 to mass 28 ratios are substantially larger than the uncertainties for the mass 19 to mass 18 ratios.

Because different modes were used to determine the mass 19 to mass 18 ratio and the mass 29 to mass 28 ratio, the measurements were taken on different days when either high- or low-resolution ion measurements were conducted. For this reason, there is no one-to-one correspondence between the observations in the top and bottom panels in Fig. 7 and, for example,
Table 3. Time intervals and spacecraft location for the DFMS ion observations that were used to determine the mass ratios in Fig. 7.

\begin{tabular}{cccc}
\hline \hline Date/time & $\begin{array}{c}\text { mass } \\
\text { ratio }\end{array}$ & $\begin{array}{c}\text { Longitude } \\
\text { range }\left(^{\circ}\right)\end{array}$ & $\begin{array}{c}\text { Latitude } \\
\text { range }\left(^{\circ}\right)\end{array}$ \\
\hline 30 Oct. 2014 & $29 / 28$ & -180 to -140 & -42 \\
2130-2310 UT & & & +19 \\
\hline $\begin{array}{c}\text { 4-5 November 2014 } \\
\text { 2300-0130 UT }\end{array}$ & $29 / 28$ & -31 to -29 & +45 to +50 \\
\hline $\begin{array}{c}\text { 28-29 November 2014 } \\
\text { 2220-1050 UT }\end{array}$ & $29 / 28$ & +42 to +111 & +46 to -28 \\
\hline 20 November 2014 & $19 / 18$ & -123 to -31 & -26 to -55 \\
0140-0450 UT & & & \\
\hline 23 November 2014 & $19 / 18$ & -148 to -17 & -54 to +16 \\
0030-0500 UT & & & +145 to -7 \\
\hline 27 November 2014 & $19 / 18$ & -140 \\
0030-0520 UT & & & +12 to +19 \\
\hline 29 November 2014 & $19 / 18$ & -43 to -6 & \\
1230-1400 UT & & & \\
\hline 02 December 2014 & $19 / 18$ & -122 to +53 & +14 \\
1540-2200 UT & & & \\
\hline
\end{tabular}

Notes. All measurements were made at $30 \mathrm{~km}$ from the comet.

there are only a few high-resolution measurements when the total pressure was greater than $2 \times 10^{7} \mathrm{~cm}^{-3}$.

The mass 19 to mass 18 ratio rarely exceeds 1 . For most total neutral densities in a limited range from (1 to 3$) \times 10^{7} \mathrm{~cm}^{-3}$, the ratio is approximately 0.5 . In contrast, the mass 29 to mass 28 ratios have two different ranges. When the total neutral density is about $1 \times 10^{7} \mathrm{~cm}^{-3}$, the mass 29 to mass 28 ratio is about 0.2 . However, when the total neutral density is greater than $2 \times 10^{7} \mathrm{~cm}^{-3}$, the mass 29 to mass 28 ratio is larger than 1 . The ratios for neutral density greater than $2 \times 10^{7} \mathrm{~cm}^{-3}$ have relatively large uncertainties due to counting statistics, especially for mass 29. The solid and dashed blue lines are discussed in the next section. 

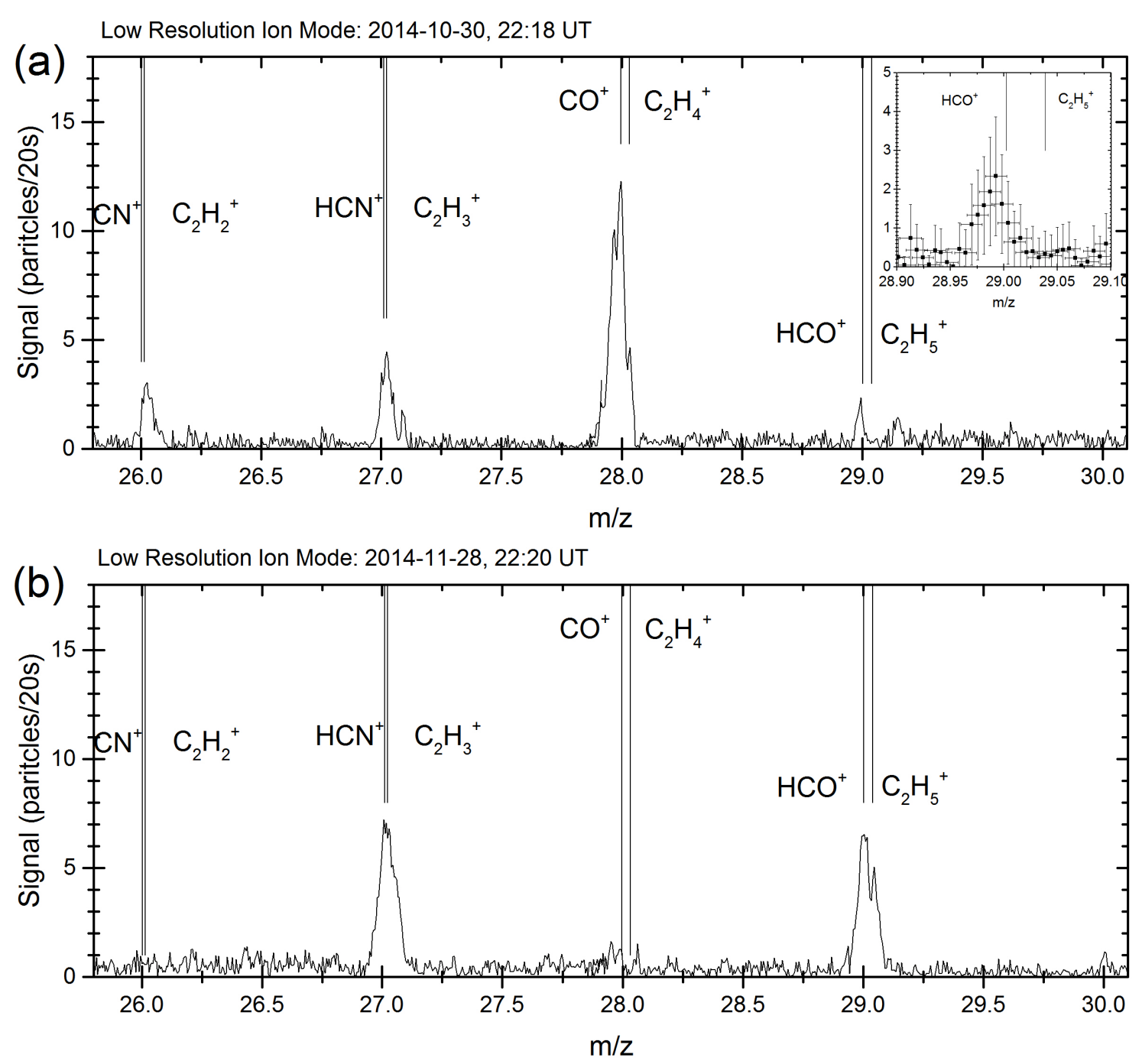

Fig. 6. Low-resolution ion spectra from mass 26 to $30 \mathrm{u} / \mathrm{e}$ for two different time periods. The mass resolution is insufficient to resolve $\mathrm{CN}^{+}$from $\mathrm{C}_{2} \mathrm{H}_{2}^{+}$or $\mathrm{HCN}^{+}$from $\mathrm{C}_{2} \mathrm{H}_{3}^{+}$at masses 26 and 27, respectively. In the top panel, clear evidence is shown that $\mathrm{CO}^{+}$dominates mass 28 and $\mathrm{HCO}^{+}$ dominates mass 29 . The inset shows a zoom-in for mass 29 , the smallest peak. The error bars in the inset are dominated by the ion statistical uncertainties in the signal and uncertainties in the mass calibration are given as horizontal error bars. The bottom panel shows very little $\mathrm{CO}^{+}$and there may be a contribution from $\mathrm{C}_{2} \mathrm{H}_{5}^{+}$to mass 29 . The bottom panel also shows a possible peak at mass 30 .

\section{Modeling the ion-neutral chemistry of $\mathrm{H}_{3} \mathrm{O}^{+}$ and $\mathrm{HCO}^{+}$}

The mass 19 to mass 18 and mass 29 to mass 28 ratios provide a measure of the extent of ion-neutral chemistry in the coma. $\mathrm{H}_{3} \mathrm{O}^{+}$and $\mathrm{HCO}^{+}$are created from ion-neutral collisions, primarily the two ion-neutral reactions with $\mathrm{H}_{2} \mathrm{O}$ and $\mathrm{CO}$ in Eqs. (1) and (2). As pointed out in the introduction, ions are created in the coma by photoionization, charge-exchange with solar wind ions, and electron impact ionization with solar wind and cometary electrons. Of these ionization processes, photoionization is dominant, providing $75 \%$ of the ions in the coma (Vigren \& Galand 2013). For $\mathrm{H}_{2} \mathrm{O}^{+}$and $\mathrm{CO}^{+}$, the dominant reactions are:

$$
\begin{aligned}
& \mathrm{H}_{2} \mathrm{O}+\mathrm{h} v \rightarrow \mathrm{H}_{2} \mathrm{O}^{+}+\mathrm{e}^{-} \quad \text { Rate: } 4.88 \times 10^{-8} \mathrm{~s}^{-1} \text { at } 3 \mathrm{AU} \\
& \mathrm{CO}+\mathrm{h} v \rightarrow \mathrm{CO}^{+}+\mathrm{e}^{-} \quad \text { Rate: } 5.63 \times 10^{-8} s^{-1} \text { at } 3 \mathrm{AU} .
\end{aligned}
$$

Thus, $\mathrm{H}_{2} \mathrm{O}^{+}$and $\mathrm{CO}^{+}$are created primarily by the photoionization processes in Eqs. (3) and (4). $\mathrm{CO}_{2}$ is photoionized into $\mathrm{O}$ and $\mathrm{CO}^{+}$, but at a rate 10 times lower than the one in Eq. (4).
Because the photoionization rates in Eqs. (3) and (4) are nearly the same, $\mathrm{H}_{2} \mathrm{O}^{+}$and $\mathrm{CO}^{+}$are created in the same proportion as their neutral densities. Ion-neutral reactions change this proportion because $\mathrm{H}_{2} \mathrm{O}^{+}$is converted into $\mathrm{H}_{3} \mathrm{O}^{+}$and $\mathrm{HCO}^{+}$primarily by the ion-neutral reactions in Eqs. (1) and (2). $\mathrm{CO}^{+}$is converted into $\mathrm{H}_{2} \mathrm{O}^{+}$and $\mathrm{HCO}^{+}$primarily by the reactions

$$
\begin{aligned}
& \mathrm{CO}^{+}+\mathrm{H}_{2} \mathrm{O} \rightarrow \mathrm{H}_{2} \mathrm{O}^{+}+\mathrm{CO} \text { rate constant }=1.56 \times 10^{-9} \mathrm{~cm}^{3} \mathrm{~s}^{-1} \\
& \mathrm{CO}^{+}+\mathrm{H}_{2} \mathrm{O} \rightarrow \mathrm{HCO}^{+}+\mathrm{OH} \text { rate constant }=8.40 \times 10^{-10} \mathrm{~cm}^{3} \mathrm{~s}^{-1} .
\end{aligned}
$$

There are a host of other ion-molecule reactions with other ion and neutral constituents in the coma that also modify the $\mathrm{H}_{2} \mathrm{O}^{+}$, $\mathrm{H}_{3} \mathrm{O}^{+}, \mathrm{CO}^{+}$, and $\mathrm{HCO}^{+}$number densities by producing ions at masses 18, 19, 28, and 29 (e.g. Rubin et al. 2009; Vigren \& Galand 2013). However, in the coma of a weakly outgassing comet like 67P far from perihelion, the long mean free path for ion-neutral collisions limits the number of reactions an ion will undergo as it propagates from where it is created in the coma to the Rosetta spacecraft only $30 \mathrm{~km}$ from the nucleus. 

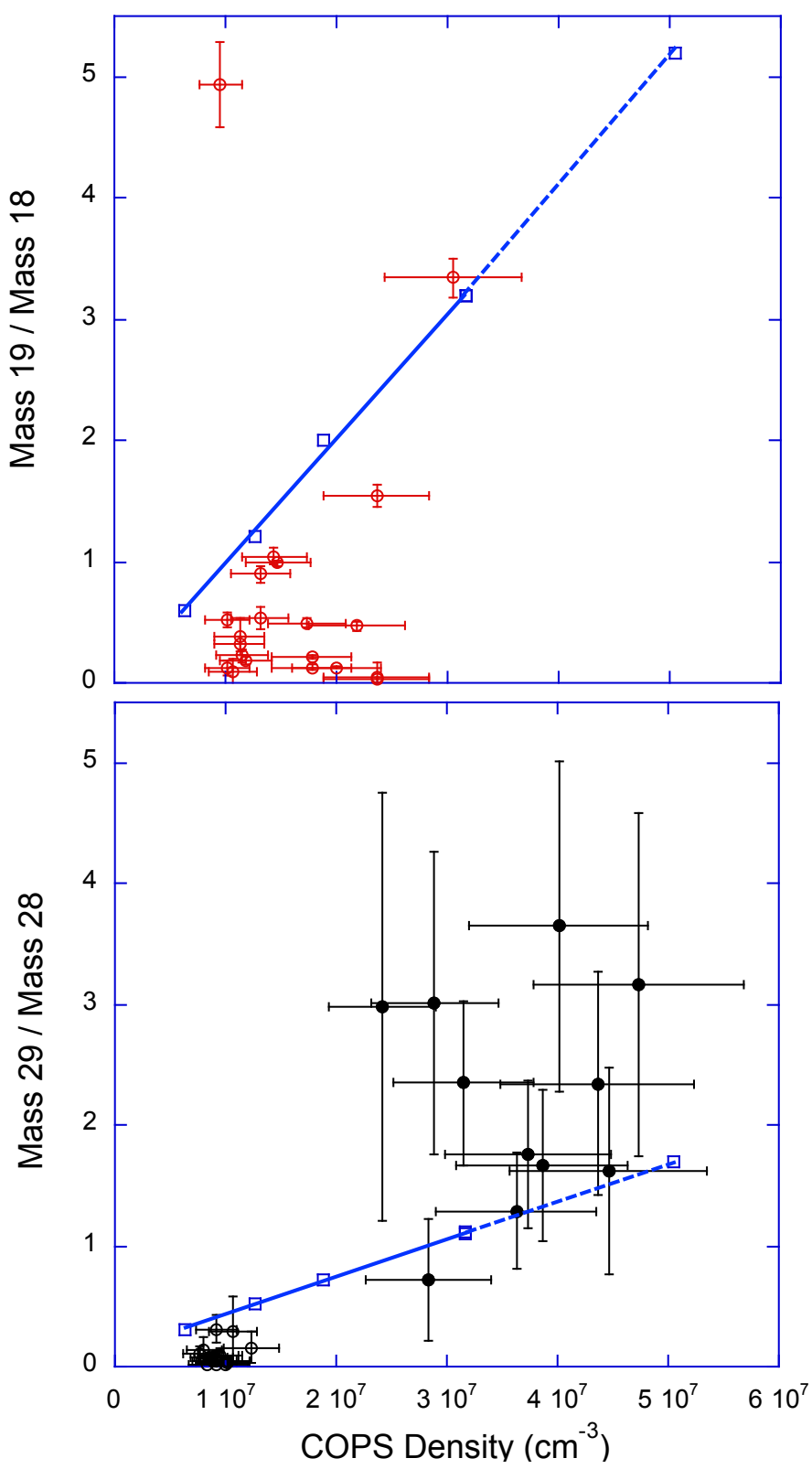

Fig. 7. Top panel: ion mass $19 /$ mass $18\left(\mathrm{H}_{3} \mathrm{O}^{+} / \mathrm{H}_{2} \mathrm{O}^{+}\right)$and bottom panel: ion mass $29 /$ mass $28\left(\left(\mathrm{HCO}^{+}\right.\right.$and possibly $\left.\left.\mathrm{C}_{2} \mathrm{H}_{5}^{+}\right) / \mathrm{CO}^{+}\right)$versus total neutral density at the Rosetta spacecraft. All measurements were made $30 \mathrm{~km}$ from the comet for the time intervals in Table 3 . The $\mathrm{H}_{3} \mathrm{O}^{+} / \mathrm{H}_{2} \mathrm{O}^{+}$ratio is mostly lower than 1 for neutral densities lower than about $2.5 \times 10^{7} \mathrm{~cm}^{-3}$. Similarly, the $\mathrm{HCO}^{+} / \mathrm{CO}^{+}$ratio is much lower than 1 for total neutral densities near $1 \times 10^{7} \mathrm{~cm}^{-3}$. The low number densities of protonated molecules indicate that, at low outgassing rates, ion-neutral chemistry is weak in the coma. For higher outgassing rates, the $\mathrm{HCO}^{+} / \mathrm{CO}^{+}$ratio can be much greater than 1 , possibly indicating enhanced ion-neutral chemistry. The blue lines show results from the model in Sect. 5. The observed mass 19/mass 18 ratio is consistently lower than the predicted ratio while the observed mass 29/mass 28 ratio agrees well with the predicted ratio, particularly at higher total neutral densities.

Here, the limited number of collisions in the coma is used as a basic constraint to create a simple coma chemistry model that predicts the maximum $\mathrm{H}_{3} \mathrm{O}^{+} / \mathrm{H}_{2} \mathrm{O}^{+}$and $\mathrm{HCO}^{+} / \mathrm{CO}^{+}$ratios as a function of outgassing rate from the comet. In the model, neutral $\mathrm{H}_{2} \mathrm{O}$ and $\mathrm{CO}$ propagate away from the comet with velocities of $0.7 \mathrm{~km} \mathrm{~s}^{-1}$ (Gulkis et al. 2015) and with a neutral density that is highest at the comet and decreases as $1 / r^{2}$, where $r$ is the radial distance from the comet. These neutrals are ionized by solar photons at rates given in Eqs. (3) and (4). The coma is not in photo-chemical equilibrium. If there were no ion-neutral chemistry, then the density profile of $\mathrm{H}_{2} \mathrm{O}^{+}$and $\mathrm{CO}^{+}$as a function of distance from the comet would be determined by a competition between the $1 / r^{2}$ density decrease and the density increase through additional ionization of neutrals in the coma.

$\mathrm{H}_{3} \mathrm{O}^{+}$and $\mathrm{HCO}^{+}$are produced through interaction of $\mathrm{H}_{2} \mathrm{O}^{+}$ with $\mathrm{H}_{2} \mathrm{O}$ and $\mathrm{CO}$ in the coma. Production of these ions and removal of $\mathrm{H}_{2} \mathrm{O}^{+}$occurs at rates in Eqs. (1) and (2). Similarly, $\mathrm{H}_{2} \mathrm{O}^{+}$and $\mathrm{HCO}^{+}$are produced through interaction of $\mathrm{CO}^{+}$with $\mathrm{H}_{2} \mathrm{O}$ in the coma. Production of these ions and removal of $\mathrm{CO}^{+}$ occurs at rates in Eqs. (5) and (6). Ions produced by the reactions in Eqs. (1), (2), (5), and (6) should continue to react with water in the coma, modifying the number densities of the four ions of interest, (i.e., $\mathrm{H}_{3} \mathrm{O}^{+}, \mathrm{H}_{2} \mathrm{O}^{+}, \mathrm{HCO}^{+}$, and $\mathrm{CO}^{+}$). However, in this simplified model of the ionized coma, only one ion-neutral collision occurs between the initial ionization near the comet and the arrival at the spacecraft $30 \mathrm{~km}$ away. Thus, secondary ionneutral reactions are artificially eliminated from the model, as are reactions that create $\mathrm{C}_{2} \mathrm{H}_{5}{ }^{+}$(mass 29) and $\mathrm{C}_{2} \mathrm{H}_{4}{ }^{+}$(mass 28) from organic molecules such as $\mathrm{C}_{2} \mathrm{H}_{6}$. In this simple model, all of the mass 29 and 28 come from $\mathrm{HCO}^{+}$and $\mathrm{CO}^{+}$, respectively.

By not allowing secondary ion-neutral reactions, loss processes for mass 19 and mass 29 are eliminated and loss processes for mass 18 and mass 28 are included. With this preferential selection, the ratios of mass 19/ mass 18 and mass 29/ mass 28 are maximized (at least to the extent that $\mathrm{HCO}^{+}$dominates mass 29 and $\mathrm{CO}^{+}$dominates mass 28 ).

The coupled rate Eqs. (1) through (6) were solved numerically for a family of outgassing rates from $5 \times 10^{25}$ molecules $/ \mathrm{s}$ (corresponding to a density of $6 \times 10^{6} \mathrm{~cm}^{-3}$ at $30 \mathrm{~km}$ from the comet, assuming a density that depends on $1 / r^{2}$ ) to $2.5 \times$ $10^{26}$ molecules/s (corresponding to a density of $3.2 \times 10^{7} \mathrm{~cm}^{-3}$ at $30 \mathrm{~km}$ from the comet). In the model, the change in the outgassing rate is used to match the observed neutral density at the spacecraft. The neutral coma was assumed to be $80 \%$ water and $20 \% \mathrm{CO}$. The results of this numerical solution are shown in Figs. 8 and 9. Panels a through $\mathrm{f}$ in these figures are (a) and (b), the number densities of $\mathrm{H}_{2} \mathrm{O}^{+}$and $\mathrm{H}_{3} \mathrm{O}^{+}$, (c) the ratio of $\mathrm{H}_{3} \mathrm{O}^{+} / \mathrm{H}_{2} \mathrm{O}^{+}$, (d) and (e), the number densities of $\mathrm{CO}^{+}$and $\mathrm{HCO}^{+}$, and (f) the ratio of $\mathrm{HCO}^{+} / \mathrm{CO}^{+}$.

The number densities of all ions in Figs. 8 and 9 have maxima very near the comet and decrease at a rate that is slower than $1 / r^{2}$ farther away from the comet (thus the outgassing rate is not simply related to the density at $30 \mathrm{~km}$ from the comet by $\left.1 / r^{2}\right)$. Most of the ions and the ion-neutral reactions occur near the comet where the neutral density is highest. As the ions and neutrals propagate away from the nucleus, the $\mathrm{H}_{3} \mathrm{O}^{+}$and $\mathrm{HCO}^{+}$number densities decrease more slowly than those of $\mathrm{H}_{2} \mathrm{O}^{+}$and $\mathrm{CO}^{+}$because the protonated molecules are preferentially created from the parent molecules in the coma.

The solid and dashed lines in Fig. 7 show the predicted mass 19 to mass 18 and the mass 29 to mass 28 ratios at $30 \mathrm{~km}$ from the comet as a function of density (the dashed lines are linear extrapolations of the predictions from the model). Comparing the predictions and observations in Fig. 7, it is clear that the observed and predicted mass ratios agree reasonably well, but the observed ratios are consistently lower than the predicted ratios for low coma densities (below $\sim 2 \times 10^{7} \mathrm{~cm}^{-3}$ ). The predicted ratios are expected to be higher than the observed ones because there are no loss terms in the model for mass 19 or 

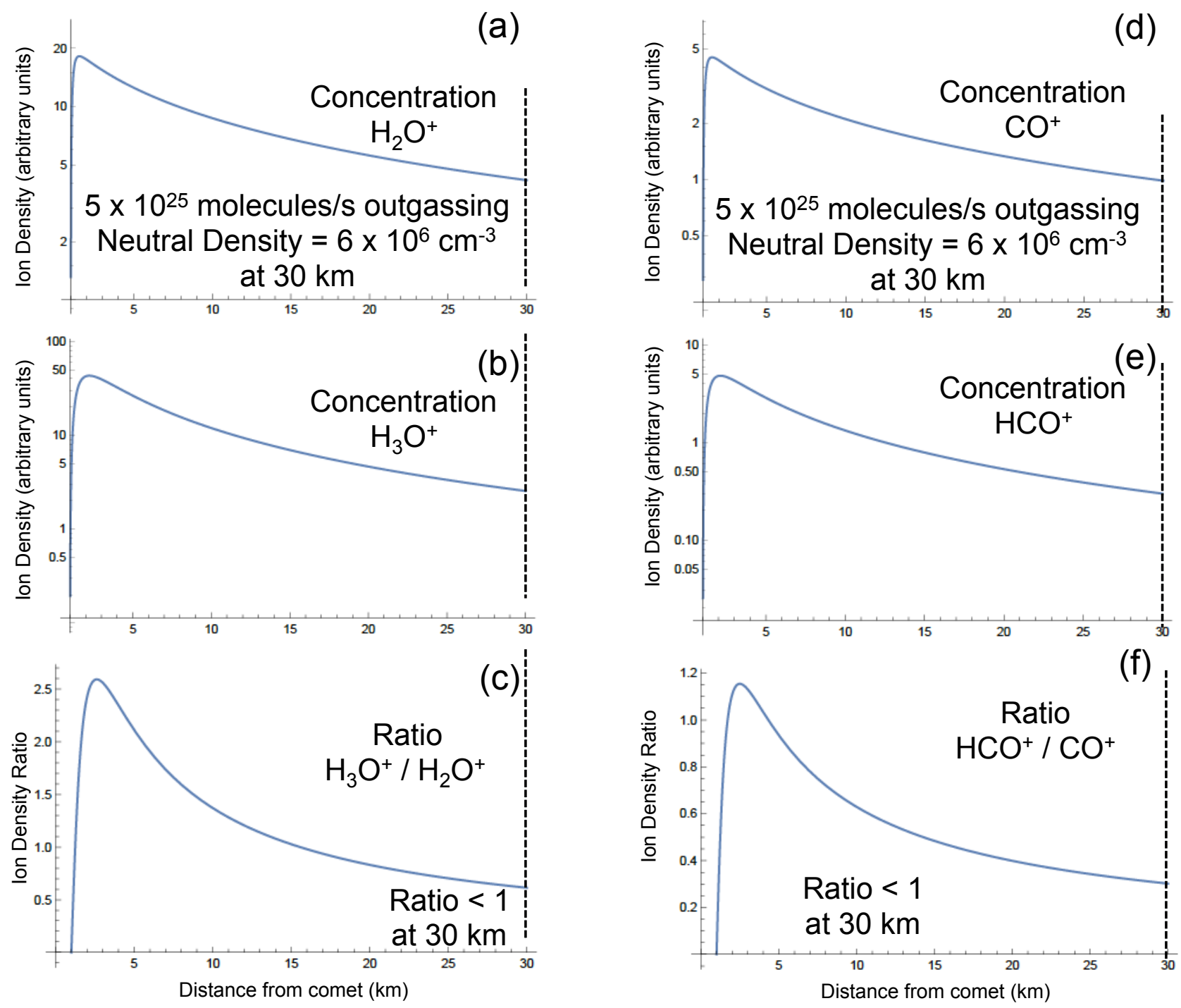

Fig. 8. Results from the simplified coma model for a water-dominated coma and low outgassing rate. All ion number densities decrease with increasing distance from the comet because of competing factors of the $1 / r^{2}$ density decrease and the increases and decreases due to ionization and ion-neutral chemistry. Whereas the chemical equations that govern the $\mathrm{H}_{3} \mathrm{O}^{+}$and $\mathrm{HCO}^{+}$number densities have no loss terms in this simple model, the equations that govern the $\mathrm{H}_{2} \mathrm{O}^{+}$and $\mathrm{CO}^{+}$number densities do have loss terms. Therefore, the $\mathrm{H}_{3} \mathrm{O}^{+}$and $\mathrm{HCO}^{+}$number densities decrease more slowly than those for $\mathrm{H}_{2} \mathrm{O}^{+}$and $\mathrm{CO}^{+}$. At $30 \mathrm{~km}$ from the comet, the $\mathrm{H}_{3} \mathrm{O}^{+} / \mathrm{H}_{2} \mathrm{O}^{+}$and $\mathrm{HCO}^{+} / \mathrm{CO}^{+}$ratios are both lower than 1 , indicating weak ion-neutral chemistry for this low outgassing case.

mass 29 , when in reality, there are several paths that may reduce the densities at these masses.

The predicted mass 29 to mass 28 ratios in Fig. 7 agree reasonably well with the observed ratios over the full range of neutral densities. Both show an increasing ratio with increasing density. The observations at higher density (solid symbols in the bottom panel in Fig. 7) were obtained over two days from 29-30 November 2014 and are all from high northern latitudes. In contrast, the observations at lower density were from moderate northern and high southern latitudes. The location of these observations has implications on the modeling that is discussed in the next section, where the possible contamination of mass 29 by $\mathrm{C}_{2} \mathrm{H}_{5}{ }^{+}$is considered.

The results from this simple model were compared with three special runs of the full chemical model from Vigren $\&$ Galand (2013). The full chemical model used the same input parameters as the simple model, included only photoionization, but added $\mathrm{CO}_{2}(4 \%)$.
For $6.4 \times 10^{6} \mathrm{~cm}^{-3}$ at $30 \mathrm{~km}$ from the comet, the $\mathrm{H}_{3} \mathrm{O}^{+} / \mathrm{H}_{2} \mathrm{O}^{+}$ratio was 0.8 and the $\mathrm{HCO}^{+} / \mathrm{CO}^{+}$ratio was 0.3 . Both of these ratios agree well with the ratios from the simple model and from the observations (see Fig. 7). For $3.2 \times 10^{7}$ $\mathrm{cm}^{-3}$ at $30 \mathrm{~km}$ from the comet, the $\mathrm{H}_{3} \mathrm{O}^{+} / \mathrm{H}_{2} \mathrm{O}^{+}$ratio was 3.1 and the $\mathrm{HCO}^{+} / \mathrm{CO}^{+}$ratio was 0.5 . The $\mathrm{H}_{3} \mathrm{O}^{+} / \mathrm{H}_{2} \mathrm{O}^{+}$ratio agrees well with the ratios from the simple model and from the observations (see Fig. 7). However, the $\mathrm{HCO}^{+} / \mathrm{CO}^{+}$ratio from the full chemical model is significantly lower than the ratios from the simple model and from the observations. The primary reason why the $\mathrm{HCO}^{+} / \mathrm{CO}^{+}$ratio is so much lower in the full chemical model is that the reaction:

$\mathrm{HCO}^{+}+\mathrm{H}_{2} \mathrm{O} \rightarrow \mathrm{H}_{3} \mathrm{O}^{+}+\mathrm{CO}$ rate constant $=2.50 \times 10^{-9} \mathrm{~cm}^{3} \mathrm{~s}^{-1}$

greatly reduces the $\mathrm{HCO}^{+}$concentration and slightly increases the $\mathrm{H}_{3} \mathrm{O}^{+}$concentration. If this reaction is excluded from the full chemical model, then the $\mathrm{H}_{3} \mathrm{O}^{+} / \mathrm{H}_{2} \mathrm{O}^{+}$ratio becomes 2.8 and the 

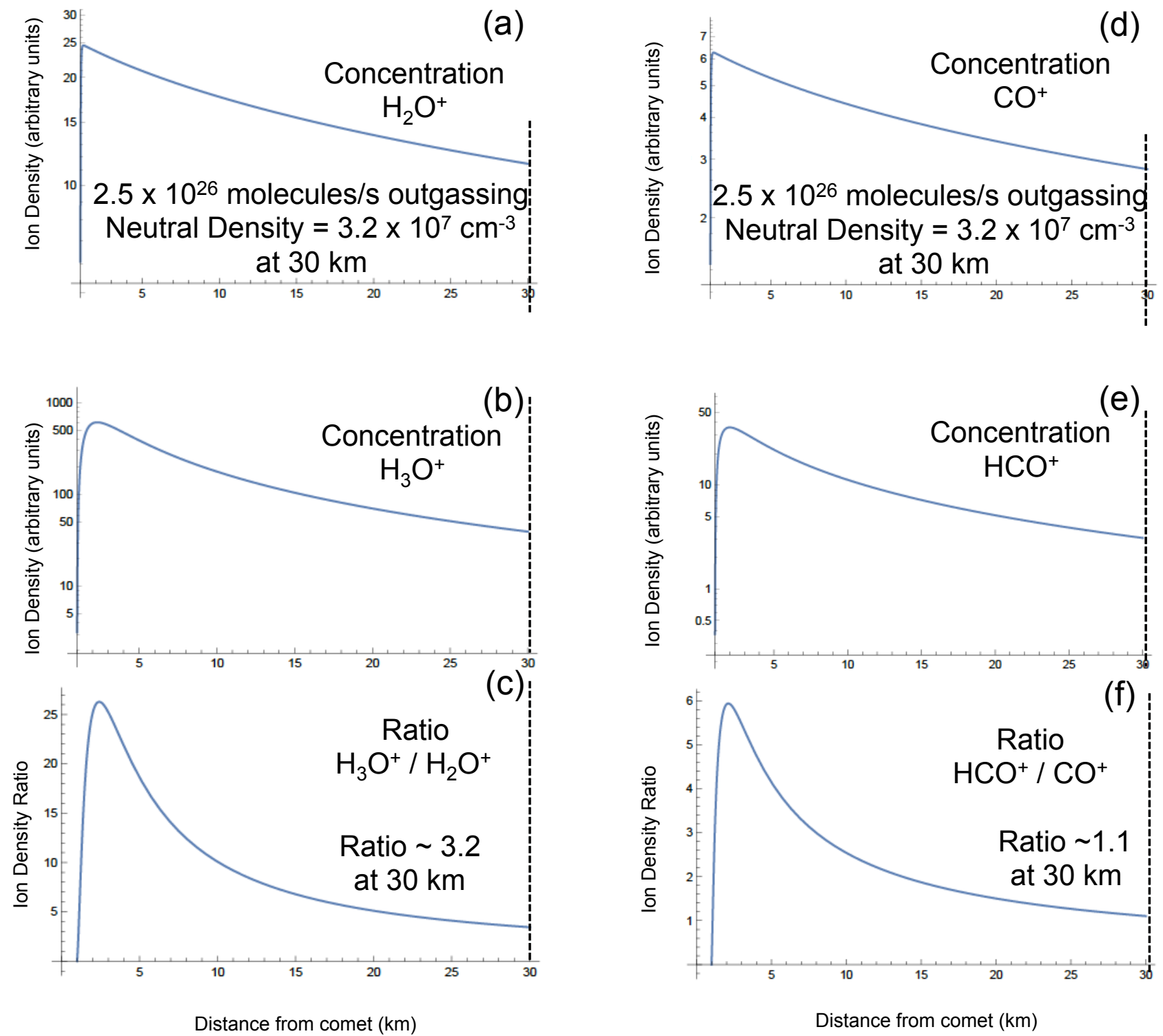

Fig. 9. Results from the simplified coma model for a water-dominated coma and high outgassing rate. Unlike the low outgassing case in Fig. 8, the $\mathrm{H}_{3} \mathrm{O}^{+} / \mathrm{H}_{2} \mathrm{O}^{+}$ratio is significantly greater than 1, indicating stronger ion-neutral chemistry for this high outgassing case. Even though there is stronger ion-neutral chemistry, the $\mathrm{HCO}^{+} / \mathrm{CO}^{+}$ratio is only slightly greater than 1 .

$\mathrm{HCO}^{+} / \mathrm{CO}^{+}$ratio becomes 2.5 . These ratios are in much better agreement with the ratios from the simple model and from the observations. The implications for these comparisons between models and observations are discussed in the next section.

\section{Discussion and conclusions}

The Rosetta encounter with comet 67P represents a unique opportunity for an up-close investigation of the neutral and ionized coma of a weakly outgassing comet that is far from perihelion. The outgassing rate at $3 \mathrm{AU}$ is $\sim 3$ orders of magnitude lower than the lowest rates observed by other spacecraft fly-bys of comets near their perihelion.

At such low outgassing rates, the solar wind, while deflected because of pickup of cometary ions, has access to the nucleus. The non-volatile neutrals in the coma (see, Wurz et al. 2015) are evidence of solar wind sputtering of these neutrals from the comet surface. Since the solar wind threads the entire neutral coma (see Fig. 2), any ion created by photoionization or charge exchange is picked up in the solar wind flow and leaves the coma. DFMS only observes newly created ions propagating radially away from the comet, before these ions are picked up. Ions created far sunward of the spacecraft and comet are picked up by the solar wind. Their energy and arrival direction are beyond the energy range and field of view of DFMS.

Rosetta DFMS observes ions in the water group with likely contributions from higher mass carbon molecules and their breakup products as well as ions at mass 26 through 29 and mass 44. These are likely $\mathrm{CN}^{+}, \mathrm{C}_{2} \mathrm{H}_{2}{ }^{+}, \mathrm{C}_{2} \mathrm{H}_{3}{ }^{+}, \mathrm{HCN}^{+}, \mathrm{CO}^{+}$, $\mathrm{C}_{2} \mathrm{H}_{5}{ }^{+}, \mathrm{HCO}^{+}$, and $\mathrm{CO}_{2}{ }^{+}$. The low-resolution mass spectra are insufficient to distinguish $\mathrm{CN}^{+}$from $\mathrm{C}_{2} \mathrm{H}_{2}{ }^{+}$and $\mathrm{C}_{2} \mathrm{H}_{3}{ }^{+}$ from $\mathrm{HCN}^{+}$. Other ions are not observed (except for $\mathrm{C}_{2} \mathrm{H}_{6}{ }^{+}$at mass 30), in large part because DFMS samples a very small region of velocity space Fig. 3. Water ion clusters were not observed by DFMS in this thin coma. Water ion clusters indicate the extent of ion-neutral interactions and are predicted in the 
coma of comet 67P when it is near perihelion and the outgassing rate is much higher (Vigren \& Galand 2009). In addition, there may be evidence of sporadic, very heavy water clusters or ice crystals in the IES observations (Burch et al. 2015; Gombosi et al. 1991).

Another indication of the extent of the ion-neutral chemistry is the formation of protonated molecules such as $\mathrm{H}_{3} \mathrm{O}^{+}$ and $\mathrm{HCO}^{+}$. The mass 19 to mass 18 and mass 29 to mass 28 ratios in Fig. 7 show that protonation is weak in the coma when the density at the spacecraft and outgassing rates are low $\left(6 \times 10^{6} \mathrm{~cm}^{-3}\right.$, corresponding to $\sim 5 \times 10^{25}$ molecules $\left./ \mathrm{s}\right)$. Significantly more protonation occurs when the outgassing rate is about three times higher $\left(3.2 \times 10^{7} \mathrm{~cm}^{-3}\right.$, corresponding to $\sim 2.5 \times 10^{26}$ molecules/s).

A simple model that used a limited set of reactions of $\mathrm{H}_{2} \mathrm{O}$ and $\mathrm{CO}$ was constructed to predict the maximum mass 19 to mass 18 and mass 29 to mass 28 ratios in a water-dominated neutral coma of a weakly outgassing comet. Figure 7 compares the predictions from this simple model to the observations. The model predicts mass 19 to mass 18 and mass 29 to mass 28 ratios that are lower than one when the outgassing is low. However, the production of $\mathrm{H}_{3} \mathrm{O}^{+}$rapidly rises as the outgassing rate increases and the production of $\mathrm{HCO}^{+}$rises less rapidly. At higher outgassing rates, the simple model is not consistent with observations for the mass 19/mass 18 ratio, but is more consistent with the observation for the mass 29 /mass 28 ratio. The simple model compares well with results from special runs of a full chemical model except for mass 29/mass 28 at high outgassing rates. This favorable comparison indicates that, at least at low outgassing rates, the chemical composition is well described by this simple model. At higher outgassing rates, the full chemical model includes a significant loss term for $\mathrm{HCO}^{+}$ (Eq. (7)). This reaction is responsible for a significant reduction in the mass $29 /$ mass 28 ratio that is not seen in the observations. In this high outgassing case, the simple model, without this loss term, agrees better with the observations. The reason may be due to a different neutral composition or a different neutral temperature (as the reaction rate in Eq. (7) is dependent neutral temperature). However, there are other factors that may also affect the mass 29/mass 28 ratio (see below). Obviously, a more detailed investigation with the full model is needed to determine why there are small mass 19/mass 18 ratios when the outgassing is somewhat higher than the low outgassing rate of $5 \times 10^{25}$ molecules/s in a water-dominated neutral coma. In a full chemical model, $\mathrm{NH}_{3}$ may become important and help explain the conversion of $\mathrm{H}_{3} \mathrm{O}^{+}$into $\mathrm{H}_{2} \mathrm{O}$ and the growth of $\mathrm{NH}_{4}{ }^{+}$ in the coma (Allen et al. 1987; Geiss et al. 1991; Altwegg et al. 1993; Haider et al. 1993; Vigren \& Galand, 2013). However, the similar mass 19/mass 18 ratios from the comparison of the simple and full chemical models demonstrates that, at low outgassing, $\mathrm{NH}_{3}$ does not play a significant role. Densities above about $3 \times 10^{7} \mathrm{~cm}^{-3}$ at $30 \mathrm{~km}$ (equivalent to an outgassing rate of about $2.5 \times 10^{26}$ molecules/s) probably requires a full chemical model with additional ionization by charge exchange, a realistic electron environment (Clark et al. 2015), and a correct treatment of $\mathrm{NH}_{3}$.

One possible explanation for the high mass 29 to mass 28 ratios in Fig. 6 may be that there is a significant contribution to mass 29 from $\mathrm{C}_{2} \mathrm{H}_{5}{ }^{+}$. The origin of $\mathrm{C}_{2} \mathrm{H}_{5}{ }^{+}$is unclear because it could have $\mathrm{C}_{2} \mathrm{H}_{6}{ }^{+}, \mathrm{C}_{2} \mathrm{H}_{4}{ }^{+}$, or some higher order Carbon molecule as its parent. The low-resolution ion measurements in Fig. 6 show that, at times, there could be a contribution from $\mathrm{C}_{2} \mathrm{H}_{5}{ }^{+}$to mass 29. Thus, there are indirect suggestions that
$\mathrm{C}_{2} \mathrm{H}_{5}{ }^{+}$may be a contributor to mass 29 , but a more detailed analysis is warranted.

It is interesting that spectrum (b) in Fig. 6 was obtained when the mass 29/mass 28 ratio was high and the spacecraft was at high northern latitudes. This spectrum is representative of all observations from November 2014 at high densities in the mass 29/mass 28 panel in Fig. 7. In November 2014, the northern hemisphere was in summer, the outgassing was dominated by $\mathrm{H}_{2} \mathrm{O}$ (neutral measurements indicate that the $\mathrm{CO} / \mathrm{H}_{2} \mathrm{O}$ density ratio was approximately $10 \%$ ). In contrast, the observations from moderate northern and high southern latitudes (see Table 3 were obtained when the outgassing was low and the $\mathrm{CO} / \mathrm{H}_{2} \mathrm{O}$ and $\mathrm{CO}_{2} / \mathrm{H}_{2} \mathrm{O}$ density ratios were much higher (Hässig et al., 2015). When the $\mathrm{CO}$ and $\mathrm{CO}_{2}$ densities become high, there is more chemistry, even for a simple model that predicts the mass 19/mass 18 ratio and the mass 29/mass 28 ratio at higher outgassing rates. In particular, the reactions in Eqs. 8 and 9 compete with the reactions in Eqs. (5) and (6) to modify the $\mathrm{HCO}^{+}$ and $\mathrm{CO}^{+}$number densities.

$$
\begin{aligned}
& \mathrm{OH}^{+}+\mathrm{CO} \rightarrow \mathrm{HCO}^{+}+\mathrm{O} \text { rate constant }=8.4 \times 10^{-10} \mathrm{~cm}^{3} / \mathrm{s} \\
& \mathrm{CO}^{+}+\mathrm{CO}_{2} \rightarrow \mathrm{CO}_{2}^{+}+\mathrm{CO} \text { rate constant }=1.1 \times 10^{-9} \mathrm{~cm}^{3} / \mathrm{s}
\end{aligned}
$$

Combining additional observations with time-dependent, full chemical models that take into account a variable $\mathrm{CO} / \mathrm{H}_{2} \mathrm{O}$ density ratio in the coma may help explain the differences in the observed and predicted mass ratios and the variable contribution of $\mathrm{C}_{2} \mathrm{H}_{5}{ }^{+}$to mass 29 .

Acknowledgements. The Rosetta/ROSINA and IES teams consist of many individuals who worked over a period of more than 20 years to achieve the spectacular successes from the Rosetta mission encounter with comet 67P. The authors are deeply indebted to these individuals. Research at Southwest Research Institute was conducted under subcontract Number 1496541 from the Jet Propulsion Laboratory. Work at the Belgian Institute for Space Aeronomy is supported by the Belgian Science Policy Office through Prodex/ROSINA PEA 90020. Work at Imperial College London is supported by the consolidated grant from the Science and Technology Facilities Council (STFC) to the college. Work at LATMOS and IRAP is supported by funding from CNES. Work at the Swedish Institute of Space Physics is supported by the Swedish National Space Board.

\section{References}

Allen, M., Delitsky, M., Huntress, W., Yung, Y., \& Ip, W.-H. 1987, A\&A, 187, 502

Altwegg, K., Balsiger, H., Geiss, J., et al. 1993, A\&A, 279, 260

Altwegg, K., Balsiger, H., \& Geiss, J. 1994, A\&A, 290, 318

Anicich, V. G. 1993, J. Phys. Chem. Ref. Data, 22, 6

Balsiger, H., Altwegg, K., Buhler, F., et al. 1986, Nature, 321, 330

Balsiger, H., Altwegg, K., Bochsler, P., et al. 2007, Space Sci. Rev., 128, 745

Benna, M., \& Mahaffy, P. R. 2006, Geophys. Res. Lett., 33, L10103

Bhardwaj, A. 2003, Geophys. Res. Lett., 30, 24, PLA2-1

Bieler, A., Altwegg, K., Balsiger, H., et al. 2015, A\&A, 583, A7

Broiles, T. W., Burch, J. L., Clark, G., et al. 2015, A\&A, 583, A21

Burch, J. L., Goldstein, R., Cravens, T. E., et al. 2007, Space Sci Rev., 128, 697

Burch, J. L., Cravens, T. E., Llera, K., et al. 2015, Geophys. Res. Lett., 42, 5125

Clark, G., Broiles, T. W., Burch, J. L., et al. 2015, A\&A, 583, A24

Coates, A. J., Johnstone, A. D., Wilken, B., Jochers, K., \& Glassmeier, K.-H. 1989, J. Geophys. Res., 94, 9983

Fuselier, S. A., Feldman, W. C., Bame, S. J., Smith, E. J., \& Scarf, F. L. 1986, Geophys. Res. Lett., 13, 247

Galeev, A. A., Cravens, T. E., \& Gombosi, T. I. 1985, ApJ, 289, 807

Geiss, J., Altwegg, K., Anders, E., et al. 1991, A\&A, 247, 226

Gombosi, T. I., Burch, J. L., \& Horányi, M. 2015, A\&A, 583, A23

Gulkis, S., Allen, M.; von Allmen, P., et al. 2015, Science, 347, 0709

Haider, S. A., \& Bhardwaj, A. 2005, Icarus, 177, 196

Haider, S. A., Bhardwaj, A., \& Singhal, R. P. 1993, Icarus, 101, 234 
Hässig, M., Altwegg, K., Balsiger, H., et al 2015, Science, 347, 0276

Hill, T. W., Thomsen, M. F., Tokar, R. L., et al. 2012, J. Geophys. Res., 117, A5

Huebner, W. F., D. C., Boice, H. U., Schmidt, \& Wegmann, R. 1991, Structure of the coma: chemistry and solar wind interaction, in Comets in the PostHalley Era, eds. R. L. Newburn et al. (The Netherlands: Kluwer Academic Publishers), 2, 907

Huebner, W. F., Keady, J. J., \& Lyon, S. P. 1992, Astrophys. Space Sci., 195, 1

Ip, W. H. 2004, Global solar wind interaction and ionospheric dynamics, in Comets II, eds. M. Festou et al. (Arizona, USA: University of Arizona Press), 605

Ip, W. H., \& Axford, I. 1987, Nature, 325, 418

Neubauer, F. M., Glassmeier, K. H., Pohl, M., et al. 1986, Nature, 321, 352
Nilsson, H., Stenberg Wieser, G., Behar, Et., et al. 2015, Science, 347, 0571

Rubin, M., Hansen, K. C., Gombosi, T. A., et al. 2009, Icarus, 199, 505

Rubin, M., Altwegg, K., Balsiger, H., et al. 2015, Science, 348, 232

Schläppi, B. 2011, Ph.D. Thesis, University of Bern

Schmidt, H. U., \& Wegmann, R. 1982, Plasma flow and magnetic fields in comets, ed. L. L. Wilkening (University of Arizona Press), 538

Shelley, E. G., Fuselier, S. A., Balsiger, H., et al. 1987, A\&A, 187, 304

Vigren, E., \& Galand, M. 2013, ApJ., 772

Wegmann, R., Schmidt, H. U., Huebner, W. F., \& Boice, D. C. 1987, A\&A 187, 339

Wurz, P., Rubin, M., Altwegg, K., et al. 2015, A\&A, 583, A22 